Alexandre Alves de Souza de Oliveira Dias'

Louisy Sanchez Santos"

Priscila Soares Sabbadini"I"

Cíntia Silva Santos ${ }^{\text {III }}$

Feliciano Correa Silva Junior'

Fátima Napoleão"'I

Prescilla Emy Nagao"'

Maria Helena Simões Villas-

Bôas'

Raphael Hirata Junior"II

Ana Luíza Mattos Guaraldi"I

Departamento de Imunologia. Instituto Nacional de Controle e Controle de Qualidade em Saúde. Fundação Oswaldo Cruz. Rio de Janeiro, RJ, Brasil

Pós-Graduação em Ciências Médicas. Faculdade de Ciências Médicas (FCM). Universidade do Estado do Rio de Janeiro (UERJ). Rio de Janeiro, RJ, Brasil

III Laboratório de Difteria e Corinebactérias de Importância Clínica. FCM-UERJ. Rio de Janeiro, RJ, Brasil

Correspondência | Correspondence: Alexandre Alves de Souza de Oliveira Dias Departamento de Imunologia Instituto Nacional de Controle e Controle de Qualidade em Saúde

Fundação Oswaldo Cruz

Av. Brasil, 4365

21040-900 Rio de Janeiro, RJ, Brasil

E-mail: alexandre.dias@incqs.fiocruz.br

Recebido: 25/11/2010

Aprovado: 27/5/2011

Artigo disponível em português e inglês em: www.scielo.br/rsp

\section{Difteria pelo Corynebacterium ulcerans: uma zoonose emergente no Brasil e no mundo}

\section{Corynebacterium ulcerans diphtheria: an emerging zoonosis in Brazil and worldwide}

\begin{abstract}
RESUMO
O artigo revisa a literatura sobre a emergência de infecções humanas causadas por Corynebacterium ulcerans em diversos países, incluindo o Brasil. Foi realizada análise de artigos publicados entre 1926 e 2011 nas bases Medline/PubMed e SciELO, bem como artigos e informes do Ministério da Saúde. Apresenta-se um esquema de triagem, rápido, econômico e de fácil execução, capaz de permitir a realização do diagnóstico presuntivo de $C$. ulcerans e $C$. diphtheriae na maioria dos laboratórios brasileiros públicos e privados. A circulação de C. ulcerans em vários países, aliada aos recentes casos de isolamento do patógeno no Rio de Janeiro, é um alerta a clínicos, veterinários e microbiologistas sobre a ocorrência de difteria zoonótica e a circulação do C. ulcerans em regiões urbanas e rurais do território nacional e/ou da América Latina.
\end{abstract}

DESCRITORES: Infecções por Corynebacterium, epidemiologia.

Reservatórios de Doenças, veterinária. Zoonoses. Doenças

Transmissíveis Emergentes. Revisão.

\section{ABSTRACT}

The article is a literature review on the emergence of human infections caused by Corynebacterium ulcerans in many countries including Brazil. Articles in Medline/PubMed and SciELO databases published between 1926 and 2011 were reviewed, as well as articles and reports of the Brazilian Ministry of Health. It is presented a fast, cost-effective and easy to perform screening test for the presumptive diagnosis of C. ulcerans and C. diphtheriae infections in most Brazilian public and private laboratories. C. ulcerans spread in many countries and recent isolation of this pathogen in Rio de Janeiro, southeastern Brazil, is a warning to clinicians, veterinarians, and microbiologists on the occurrence of zoonotic diphtheria and C. ulcerans dissemination in urban and rural areas of Brazil and/or Latin America.

DESCRIPTORS: Corynebacterium Infections, epidemiology. Disease Reservoirs, veterinary. Zoonoses. Communicable Diseases, Emerging. Review. 


\section{INTRODUÇÃO}

A difteria é uma doença de evolução aguda com manifestações locais e sistêmicas. Essa doença permanece como uma importante causa de morbidade e mortalidade nos diferentes continentes, mesmo em países com programas de imunização infantil. ${ }^{4,35,58,82,92}$ As formas clássicas da difteria são causadas principalmente pelo Corynebacterium diphtheriae, produtor de toxina diftérica (TD), e são caracterizadas pela presença de pseudomembrana acinzentada no sítio de infecção devido aos efeitos da multiplicação desse bacilo e da resposta imune do hospedeiro. ${ }^{40,65,114}$ A TD é uma potente exotoxina de natureza protéica capaz de atuar em todos os tecidos com especial tropismo para o miocárdio, sistema nervoso, rins e supra-renais. ${ }^{40,82,93}$ Só são toxinogênicas as amostras infectadas por bacteriófagos específicos portadores do gene tox. ${ }^{33}$

A proteção contra a TD pode ser adquirida pela vacinação com o toxóide diftérico (e.g. DTP e outras combinações contendo o componente diftérico), mas não com antígenos somáticos. ${ }^{6,35, a} \mathrm{O}$ nível de imunidade diminui ao final da infância e adolescência, dependendo do calendário de vacinação e da reserva de $C$. diphtheriae na população. ${ }^{35,77} \mathrm{~A}$ difteria pode acometer indivíduos parcialmente imunizados, independentemente da idade, raça ou sexo. Um declínio parcial na imunidade, aliado à falta de reforços vacinais e a menor exposição ao bacilo, contribuem para a ocorrência esporádica de epidemias. $23,34,69,77$

Na Era da Vacinação, as diversas mudanças observadas na epidemiologia da difteria ${ }^{14,35,69}$ podem ser parcialmente justificadas pela prevalência de baixos níveis de IgG antitoxina diftérica na população de adolescentes e adultos. ${ }^{15,29} \mathrm{Na}$ década de 1990 ocorreu, no Leste Europeu, a maior epidemia de difteria registrada $(80 \%$ dos casos notificados mundialmente) após o início da vacinação em massa. A maioria dos casos e óbitos ocorreu em adultos infectados pelo clone epidêmico de $C$. diphtheriae subsp. gravis, que ainda circula na Rússia, Letônia, Lituânia e Bielo-rússia. ${ }^{89,90,112,113}$

Além das mudanças na faixa etária, têm sido observados casos de difteria com ausência de pseudomembranas e de infecções invasivas de origens diversas em indivíduos previamente submetidos à vacinação. Casos de infecções invasivas, tais como endocardite, osteomielite, artrite, pneumonia e abscessos renais, têm sido predominantemente relacionados a amostras atoxinogênicas de $C$. diphtheriae subsp. mitis. ${ }^{17,24,48,53,66,68}$

A Organização Mundial da Saúde (OMS) criou um índice Disability-Adjusted Life Year (DALY), em que cada unidade representa um ano de vida saudável perdido, por doença, internação ou mesmo óbito (levando em conta a expectativa de vida de cada país) a cada 100.000 habitantes. Os dados de 2002 sobre a mortalidade e incidência de difteria relacionaram as seguintes regiões com maiores DALYs: América Central [Haiti (> 50 DALYs)e República Dominicana], África Subsaariana [República Democrática do Congo e Serra Leoa e Ásia [Nepal e Myanmar] (> 15 DALYs). ${ }^{\mathrm{b}}$ A atual epidemia que vem ocorrendo na Índia apresenta DALYs $>7$, a cobertura vacinal é inferior a $80 \%$ e apenas $56 \%$ das crianças estão protegidas contra a difteria $(\geq 0,1 \mathrm{UI} / \mathrm{ml}){ }^{4}$

Os países das Américas do Sul e do Norte, Europa Ocidental e Oceania apresentaram índices inferiores

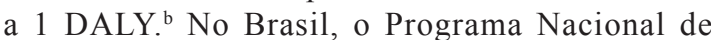
Imunizações foi estabelecido no inicio da década de 1970. ${ }^{\mathrm{c}, \mathrm{d}}$ Segundo os dados do Ministério da Saúde, atualmente a cobertura vacinal atinge $99 \%$ da população infantil. Entretanto, nas últimas décadas, casos de difteria ainda ocorrem na maioria dos estados brasileiros. ${ }^{48,66,68, e, f, g, h}$ Apenas no período de 2008/09 foram confirmados 89 casos de difteria. Em 2010, em três municípios do estado do Maranhão, onde a cobertura vacinal chega a $56 \%$, foram confirmados 27 casos de difteria (2 óbitos), sendo a maioria em crianças com esquema de vacinação completo. Não se pode descartar a possibilidade de subnotificação de casos no Brasil e em outros países em desenvolvimento devido à falta de esclarecimento da população para a busca de atendimento médico e às dificuldades de obtenção do diagnóstico clínico-laboratorial em casos de difteria, em particular quando os pacientes estão parcialmente protegidos contra a ação da TD.

\footnotetext{
a Secretaria de Saúde do Estado do Rio de Janeiro. Proporção de casos e óbitos por difteria segundo faixa etária, 1978-2002. Rio de Janeiro: Assessoria de Doenças Imunoprevisíveis; 2002.

${ }^{b}$ Wikipedia: The Free Encyclopedia. Diphtheria World Map - DALY - WHO2002 [citado 2010 nov 15]. Disponível em: http://en.wikipedia.org/ wiki/File:Diphtheria_world_map_-_DALY_-_WHO2002.svg

c Ministério da Saúde, Fundação Nacional de Saúde, Centro Nacional de Epidemiologia. Evolução temporal das doenças de notificação compulsória no Brasil de 1980 a 1998. Bol Epidemiol.1999; 3 Ed Espec:1-48.

d Ministério da Saúde, Fundação Nacional de Saúde. Difteria: situação atual da doença [citado 2002 mar 23]. Disponível em: http://www. funasa.gov.br/guia epi/htm/doencas/difteria/index.htm

e Ministério da Saúde, Fundação Nacional de Saúde, Centro Nacional de Epidemiologia. Guia de vigilância epidemiológica. 4. ed. Brasília (DF); 1998 [citado 2010 mar 10]. Difteria; capítulo 5.6. Disponível em: http://www.cro-rj.org/biosseguranca/Guia de\%Vigilancia Epidemiologica.pdf

${ }^{f}$ World Health Organization. Diphtheria. Geneva; 2010 [citado 2010 set 7]. Disponível em: http://www.who.int/topics/diphtheria/en/index.html g Santos LS, Sant'Anna LOS, Cosme LMSS, Hirata Jr RH, Mattos-Guaraldi AL. Perfis fenotípicos e genotípicos de amostras de Corynebacterium diphtheriae isoladas em recente surto epidêmico ocorrido no Maranhão. In: $44^{\circ}$ Congresso Brasileiro de Patologia Clínica; 2010 ; Rio de Janeiro, Brasil. J Bras Patol Clin, 2010;46:4.

h Ministério da Saúde, Sistema de Informação de Agravos de Notificação - SINAN. Casos confirmados de difteria: Brasil e Grandes Regiões, 1997-2006. Brasília (DF); 2007 [citado 2010 mar 10]. Disponível em: http://portal.saude.gov.br/portal/arquivos/pdf/casos_difteria.pdf
} 
A partir de meados da década de 1980, o número de casos de difteria de natureza zoonótica causada pelo $C$. ulcerans aumentou em diferentes países. Na Inglaterra, o número de casos de difteria pelo $C$. ulcerans superou o relacionado com o agente etiológico clássico, $C$. diphtheriae..$^{5,76,96,107,109,113,115}$ Apesar de o C. ulcerans toxigênico ser atualmente reconhecido em diversos países industrializados como um patógeno emergente, sua capacidade de causar doença em humanos, inclusive entre habitantes de centros urbanos, ainda é freqüentemente negligenciada. ${ }^{19,70,108}$

Desse modo, a presente revisão teve como objetivo analisar aspectos relacionados à emergência de C. ulcerans como agente etiológico da difteria zoonótica no Brasil e outros países que realizam a vacinação tríplice bacteriana (DTP), contra difteria, tétano e coqueluche, e outras combinações contendo o componente diftérico.

\section{PROCEDIMENTOS METODOLÓGICOS}

Estudos e pesquisas sobre a difteria zoonótica foram coletados a partir de busca nas bases de dados Medline/ PubMed e SciELO. As palavras utilizadas na busca foram: "diphtheria", "Corynebacterium ulcerans", "zoonotic diphtheria", "laboratorial diagnosis", "diphtheria clinical cases", "molecular epidemiology" e "infected animals", no período de 1926 a 2011. Foram excluídos aqueles com foco em descrição de casos de difteria pelo $C$. diphtheriae ocorridos fora do Brasil. Adicionalmente, foram analisados artigos em português e inglês, disponíveis em formato eletrônico, com foco em: situação da difteria no Brasil, procedimentos laboratoriais e níveis séricos de anticorpos antitoxina diftérica em adultos.

\section{ASPECTOS MICROBIOLÓGICOS E CLÍNICOS}

O gênero Corynebacterium pertence ao grupo de bastonetes Gram-positivos irregulares (BGPIs), de crescimento aeróbico, imóveis, não esporulados e catalase-positivos. Nos últimos anos foram descritas mais de 60 espécies de corinebactérias, sendo diversas relacionadas com a colonização e/ou infecção em humanos e animais. A análise filogenética de subunidades de seqüências $16 \mathrm{~S}$ rRNA permitiu identificar C. ulcerans, C. diphtheriae e Corynebacterium pseudotuberculosis como espécies distintas potencialmente produtoras de TD. ${ }^{57,91}$ C. ulcerans e $C$. pseudotuberculosis são capazes de hidrolisar a uréia, o que os diferencia presuntivamente da espécie tipo do gênero, o $C$. diphtheriae.

A espécie C. ulcerans, gelatinase-positiva e nitratonegativa e descrita por Gilbert \& Stewart em 1926, pode produzir quadros clínicos diversos, dependendo do tipo e quantidade de toxinas secretadas. ${ }^{8,36}$ Diversos estudos têm investigado os mecanismos de patogenicidade, além da produção de TD em amostras de $C$. diphthe-

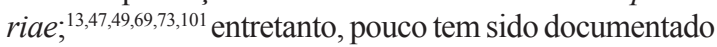

sobre os fatores de virulência de C. ulcerans. Os mecanismos de virulência descritos para C. pseudotuberculosis incluem os lipídios tóxicos associados à parede celular que podem mediar a resistência bacteriana ao ataque dos fagócitos. ${ }^{42}$ Atualmente uma exotoxina do tipo fosfolipase D (PLD) é considerada o principal fator de virulência produzido por C. pseudotuberculosis durante a infecção. PLD apresenta atividade de esfingomielinase e pode aumentar localmente a permeabilidade vascular, contribuindo para disseminação do patógeno nos tecidos do hospedeiro. ${ }^{3,50,72}$ C. ulcerans também é capaz de produzir PLD, além de TD. ${ }^{51}$

Não é recente a preocupação de que o C. ulcerans poderia apresentar o potencial de emergir como patógeno capaz de albergar o bacteriófago codificador de TD e, portanto, causar quadros de difteria clássica. Estudos mostraram que alguns bacteriófagos teriam seletividade sobre C. ulcerans não induzindo a produção de TD. ${ }^{45}$ Contudo, também foi constatada a capacidade de o bacteriófago $\beta$ infectar amostras de $C$. diphtheriae, C. pseudotuberculosis e C. ulcerans, constituindo risco para o surgimento de quadros de difteria causados por tais espécies. ${ }^{1,38,95,99} \mathrm{~A}$ variabilidade na capacidade de produção de TD entre as amostras de $C$. ulcerans já foi documentada. ${ }^{39,116}$ A maioria dos casos clínicos em humanos e animais foi relacionada com cepas produtoras de TD (Tabelas 1 e 2). ${ }^{11,18,56,62}$

Os efeitos de TD produzida pelo C. ulcerans são: freqüente ocorrência de sangramento nasal durante infecções; lesões de pele que mimetizam a difteria cutânea típica; lesões da árvore traqueobrônquica com pseudomembrana, hemorragia, comprometimento de linfonodos cervicais e morte celular por apoptose..$^{8,17,63,111,115}$ A ocorrência de necrose e ulceração da mucosa, síndromes clínicas no trato respiratório inferior, como pneumonia e nódulos pulmonares granulomatosos, foram atribuídas à produção de TD e PLD. ${ }^{16,44,52,97}$

\section{ASPECTOS EPIDEMIOLÓGICOS}

Classicamente, a espécie C. ulcerans tem sido descrita como agente etiológico de quadros diversos de infecções em animais, principalmente de mastites em gado bovino. Os primeiros casos de infecções em humanos foram normalmente associados ao consumo de leite não fervido/pasteurizado e derivados, além de casos de trabalhadores rurais portadores assintomáticos de C. ulcerans na nasofaringe. Isso mostra a capacidade desse patógeno de circular entre hospedeiros humanos e animais e de causar difteria de natureza zoonótica. , $7,43,46,52$ De modo geral, as infecções diftéricas causadas pelo C. ulcerans têm sido relacionadas com pacientes parcialmente imunizados com toxóide diftérico, resultados negativos na pesquisa de portadores/ contactantes e fonte de infecção indeterminada. ${ }^{108}$ 


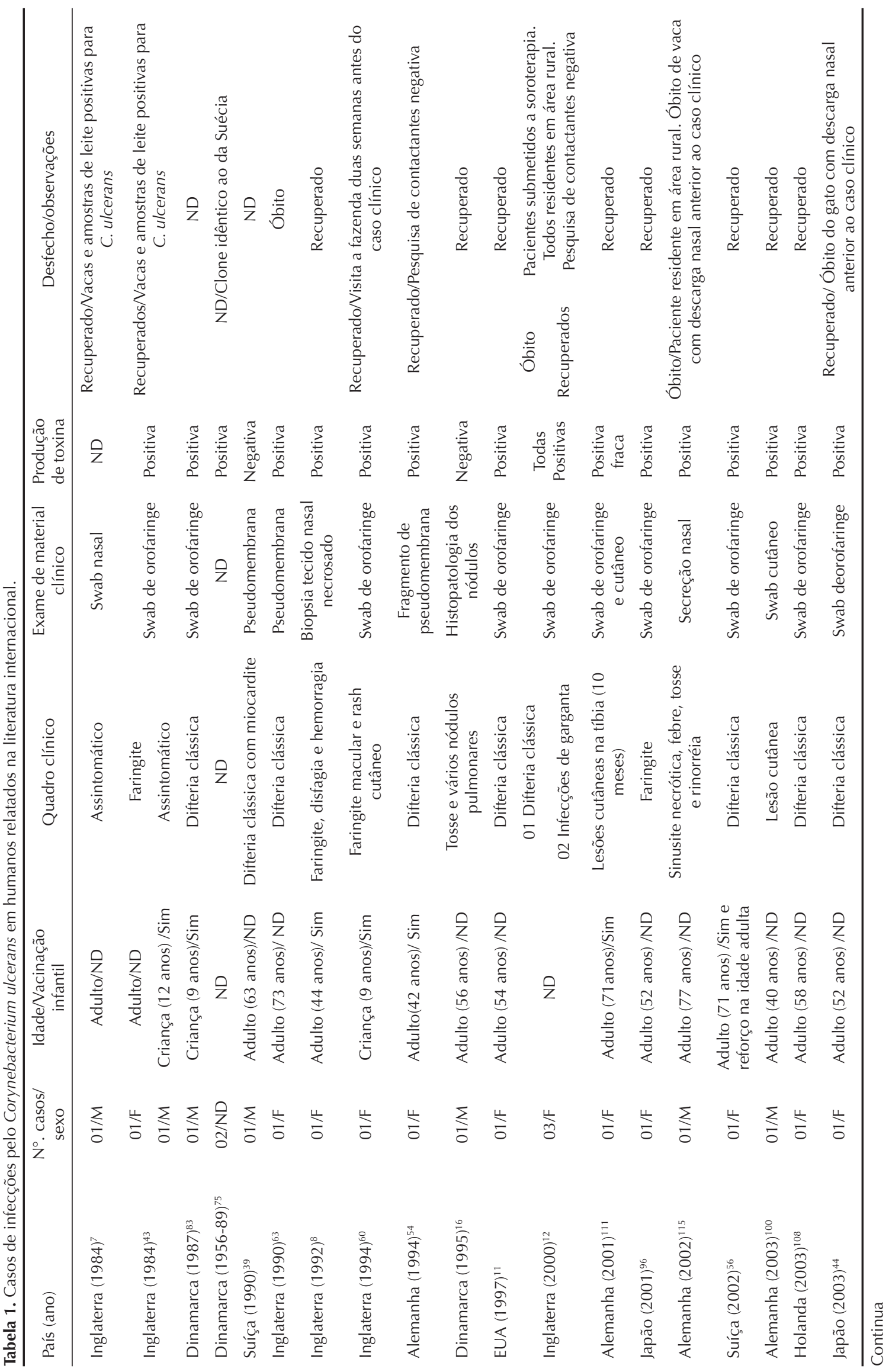




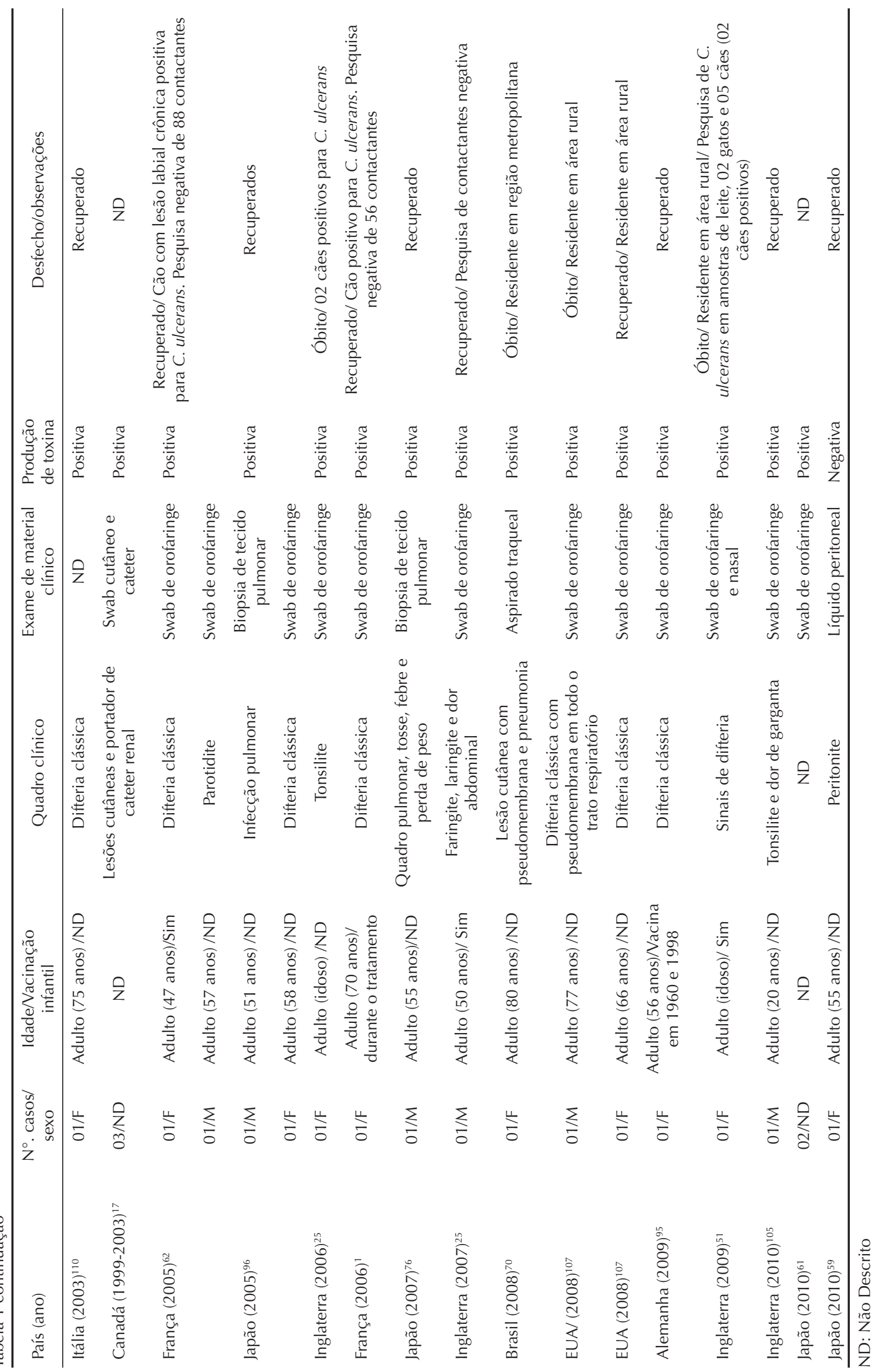




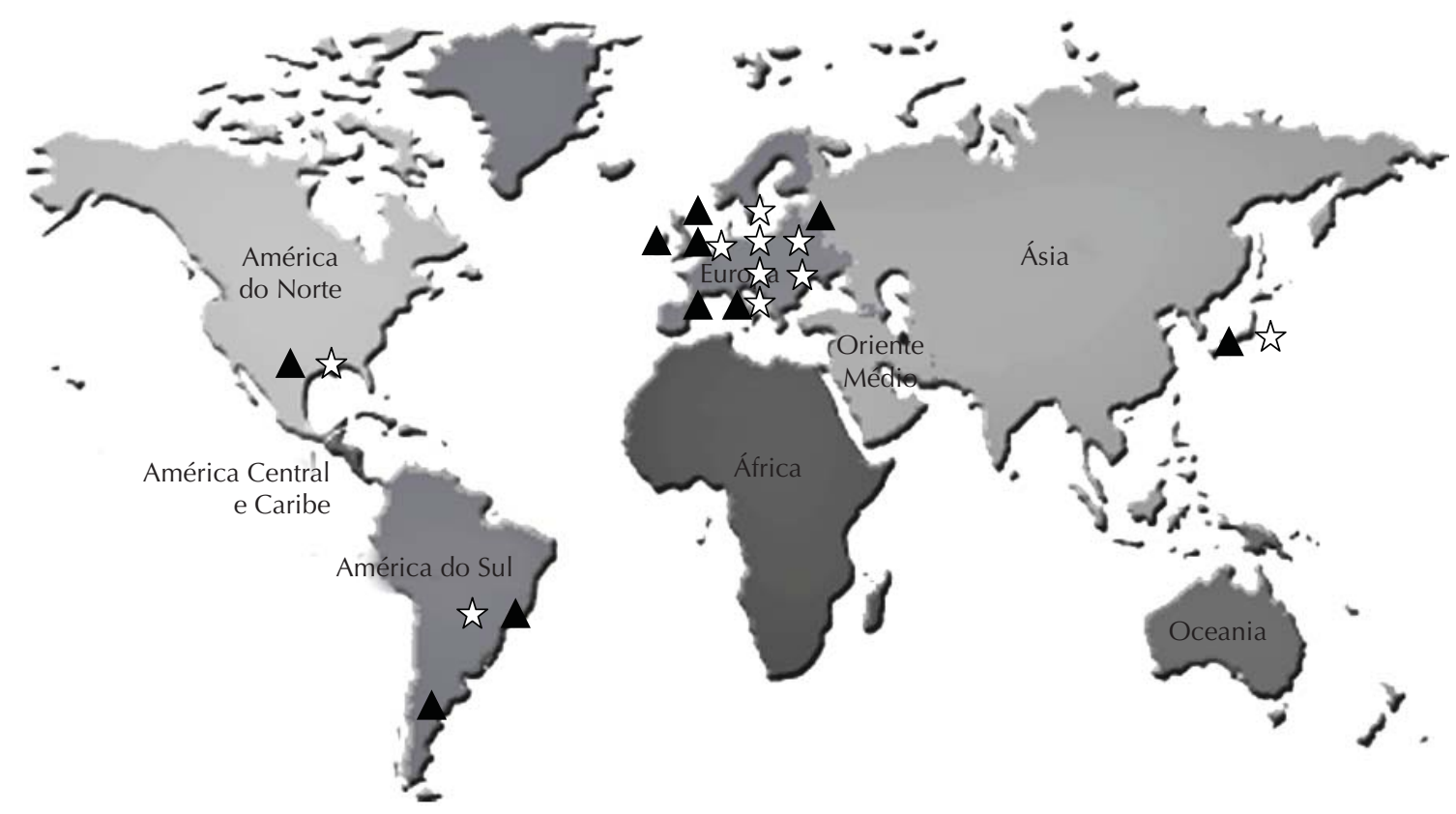

Figura 1. Distribuição mundial de casos notificados de infecções pelo Corynebacterium ulcerans em humanos (estrelas) e em animais (triângulos), 1972 a 2010.

Conforme apresentado na Tabela 1, além dos quadros com características semelhantes a difteria respiratória e cutânea, as amostras de C. ulcerans também têm sido relacionadas a outros quadros clínicos em humanos, tais como sinusite, tonsilite, faringite, pneumonia e peritonite. $\mathrm{O}$ crescente número de casos de infecções por C. ulcerans em cães e gatos desde 2006 ressalta a importância de se ampliar o conhecimento relativo aos aspectos epidemiológicos dessa zoonose emergente. Casos de infecções pelo C. ulcerans ocorridos em diversas espécies de animais, como macacos, esquilos, lontras, orcas, camelos e leões, além de cães, gatos, porcos, cabras e bovinos, também foram descritos na literatura internacional (Figura 1 e Tabela 2). $1,17,18,55,62,96,103$
Dentre os 37 estudos relacionados com infecções em humanos, foi possível determinar o sexo de 37 indivíduos e a idade em 32 oportunidades. Uma predominância de casos $(n=24 ; 65 \%)$ e óbitos $(n=5$; $71 \%$ ) foi observada em indivíduos do sexo feminino. Interessantemente, a maioria das infecções em animais pelo $C$. ulcerans também ocorreu em fêmeas (mastites). Wagner et $\mathrm{al}^{113}$ (2010) realizaram um levantamento dos casos de infecções por C. ulcerans e $C$. diphtheriae na Inglaterra, de 1986 a 2008, e também encontraram predominância de casos em mulheres (76\%), assim como óbitos (75\%). A média de idade dos portadores de C. ulcerans (38 anos) foi mais elevada que a média dos portadores de $C$. diphtheriae (15 anos). Do mesmo modo, a Tabela 1 mostra tendência de os portadores de C. ulcerans terem idade elevada, em média de 53

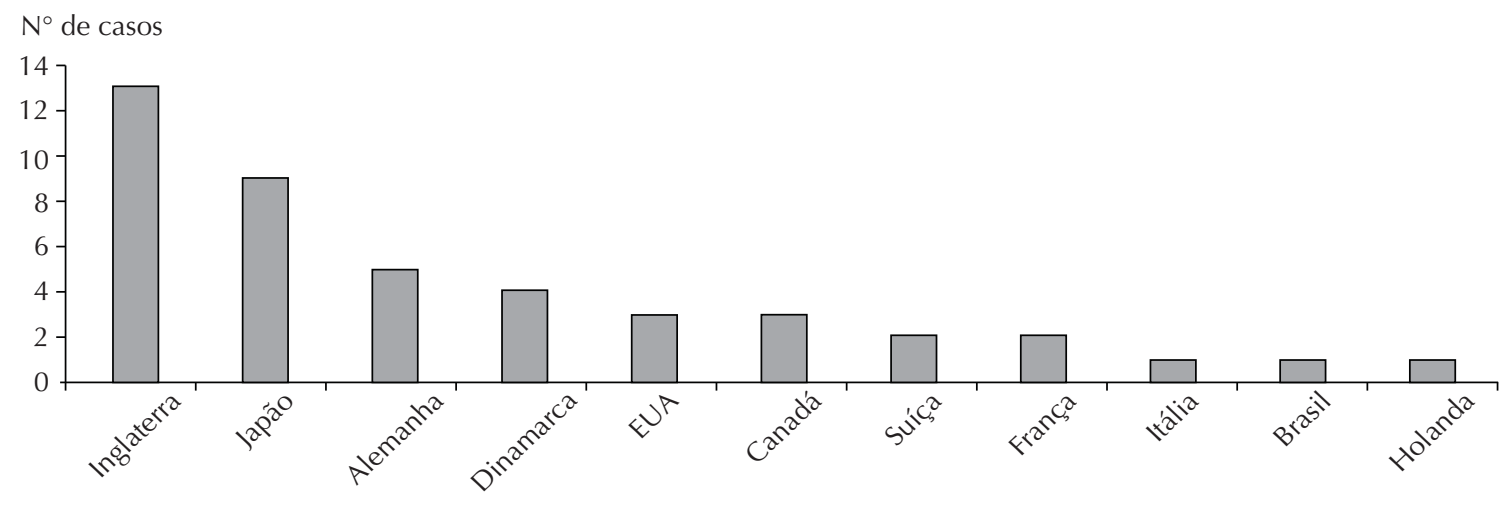

Figura 2. Distribuição nos diversos países dos casos de infecção humana por Corynebacterium ulcerans relatados na literatura disponível, 1984 a 2010. 


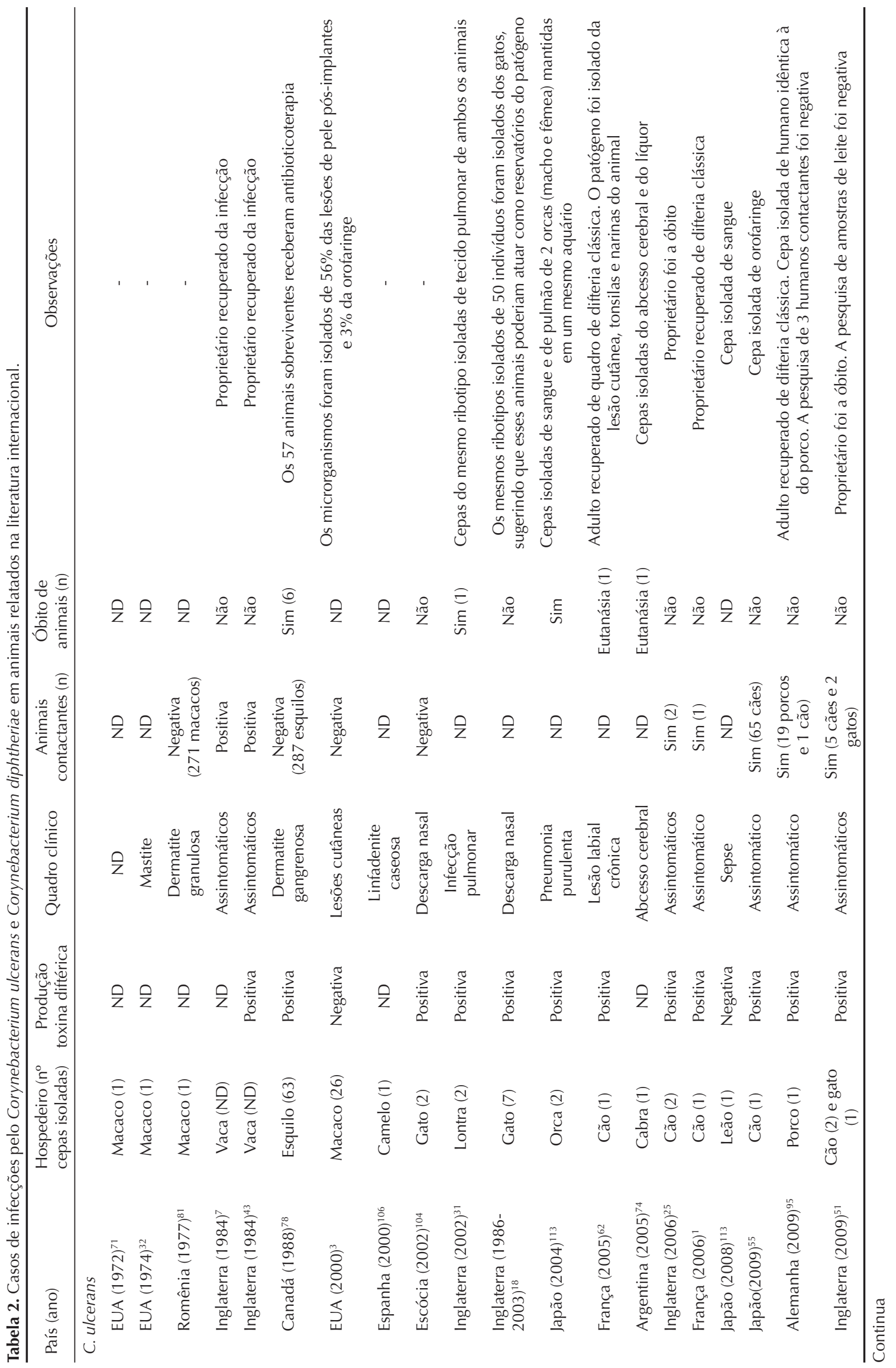


anos, a maioria com mais de 60 anos, o que contrasta fortemente com o perfil etário dos casos de infecção por $C$. diphtheriae no Brasil e no mundo.

Conforme apresentado na Tabela 1 e Figuras 1 e 2, o $C$. ulcerans vem sendo motivo crescente de preocupação das autoridades em saúde pública em muitos países: Inglaterra, ${ }^{25,113}$ França, ${ }^{1}$ Alemanha, ${ }^{100}$ Holanda, ${ }^{108}$ Itália, ${ }^{110}$ Suíça, ${ }^{39,56}$ Dinamarca, ${ }^{75}$ Japão, ${ }^{44}$ Canadá $^{17}$ e Estados Unidos. ${ }^{12,13,107}$ Apenas cinco casos de infecções humanas, ocorridos na Inglaterra e Dinamarca, foram documentados em período anterior à década de 1990 . A partir de 1990, foram relatados diversos casos de pacientes humanos que não apresentavam fatores de risco associados às infecções pelo C. ulcerans, tais como consumo de leite cru ou contato com animais de fazenda. Portanto, o risco de transmissão entre pequenos animais e entre seres humanos tornou-se um motivo de preocupação. 1,17,18,55,62,70,96,107

Além de bovinos e caprinos, cães e gatos passaram a ser responsáveis pela transmissão de $C$. ulcerans para hospedeiros humanos. Para dois casos de difteria causados por C. ulcerans descritos na França (2005 e 2006) a fonte de infecção foi o cão de estimação. ${ }^{1,62}$ Ensaios de ribotipagem também têm sido realizados para determinar a relação genética entre os microrganismos isolados desses animais e de humanos. No Reino Unido foi observado que amostras toxinogênicas isoladas de gatos com corrimento nasal bilateral eram pertencentes aos mesmos ribotipos de C. ulcerans isolados de humanos infectados, mostrando a capacidade de esses animais atuarem como reservatório do patógeno. ${ }^{18,104}$ Similarmente, foi observada amostra de C. ulcerans isolada de humanos na Itália pertencente a um mesmo ribotipo encontrado em amostras isoladas na Inglaterra. ${ }^{110}$

Embora o C. diphtheriae seja classicamente considerado um patógeno humano, no ano de 2010 foram relatados casos de infecções por $C$. diphtheriae em gatos (otite severa) e em cavalo (lesão cutânea purulenta), ${ }^{41,64}$ sugerindo a emergência de potencial zoonótico também para o $C$. diphtheriae (Tabela 2).

A transmissão homem a homem do C. ulcerans ainda não foi evidenciada, mas vários pesquisadores recomendam o isolamento de pacientes infectados. ${ }^{2,7,11,43,60,70,107}$ No primeiro e único caso clínico de infecção humana por C. ulcerans notificado no Brasil, ${ }^{70} \mathrm{o}$ histórico de vacinação da paciente e a fonte de infecção eram desconhecidos. Alguns dias após a morte da paciente, um dos profissionais de saúde envolvido no caso apresentou um quadro de faringite conseqüente à exposição ao patógeno e iniciou imediatamente antibioticoterapia com eritromicina antes da coleta de material para cultura e identificação. Apesar de a cultura ter apresentado resultado negativo, o paciente apresentou sinais de miocardite em exames 
cardiológicos clínicos, incluindo ecocardiografias e repetidos eletrocardiogramas.

Ainda não foram totalmente esclarecidas as causas que contribuem para o aumento do número de casos de infecção pelo C. ulcerans em humanos e animais domésticos. Uma vez que foram observados ribotipos similares em processos infecciosos humanos e animais, é possível que algumas amostras de C. ulcerans apresentem fatores de virulência adicionais decorrentes de pressão seletiva, associados às condições socioeconômicas desfavoráveis, sobretudo em áreas de superpopulação predominada por condições higiênico-sanitárias inadequadas. Adicionalmente, em alguns países, tais como os Estados Unidos, o número de animais domésticos que vivem no interior dos lares, circulando em áreas tais como cozinhas e quartos de dormir, tem sido bastante significativo, ${ }^{i}$ favorecendo o processo de transmissão de diversos agentes e zoonoses para os seres humanos, possivelmente também o C. ulcerans. ${ }^{20}$

\section{SITUAÇÃO ATUAL NO BRASIL E NOS PAÍSES EMERGENTES}

Conforme ilustrado na Figura 1, o número de casos notificados nos países emergentes é bastante reduzido. Na América Latina, há casos descritos em animais na Argentina $^{74}$ e no Brasil, ${ }^{19}$ mas em humanos, apenas no Brasil $^{70}$ (Tabelas 1 e 2). Não há registros na literatura de isolamento de amostras de C. ulcerans na Índia, China, Oceania e todo o continente africano. Não podemos deixar de aventar a hipótese de ocorrer a circulação do patógeno pelos diferentes continentes e de que possa haver subnotificação de casos devido à carência de disponibilidade de redes de laboratórios habilitados para o isolamento e identificação do patógeno. Além do Reino Unido, poucos países apresentam rotinas laboratoriais estabelecidas e exigem a notificação compulsória de infecções humanas pelo C. ulcerans e o isolamento de amostras atoxinogênicas.

Em agosto de 2010 o Ministério da Saúde emitiu um alerta $^{j}$ sobre a situação da difteria no Brasil. Esse documento informa mudanças no perfil clínicoepidemiológico da doença, tais como ausência de pseudomembranas, desvio de faixa etária, ocorrência de difteria zoonótica e circulação de C. ulcerans e $C$. diphtheriae no País. Outros pontos destacados foram: a adoção das mesmas medidas de controle preconizadas para a espécie $C$. diphtheriae em casos confirmados de difteria por C. ulcerans; notificação, tratamento e monitoramento de todos os casos suspeitos de difteria com isolamento de cepas não produtoras de toxina, pelos profissionais da área de saúde.
No Brasil foi descrito (no ano de 2008) um único caso de infecção fatal em humanos causada por C. ulcerans ${ }^{70}$ e posteriormente (2010) foi detectada a condição de portador assintomático de um cão, ambos na área metropolitana da cidade do Rio de Janeiro (RJ). ${ }^{19}$ Resumidamente, uma idosa apresentou diversas lesões cutâneas recobertas por pseudomembranas em ambos os membros inferiores e foi a óbito em decorrência de complicação cardio-respiratória, mesmo após antibioticoterapia e soroterapia. O microrganismo isolado do trato respiratório inferior da paciente, produtor de exotoxina que apresentava diferenças na subunidade A da molécula, mostrou-se resistente aos antimicrobianos penicilina $\mathrm{G}$ (MIC $0,19 \mathrm{mg} / \mathrm{l}$ ) e clindamicina (MIC 1,5 mg/l). Variações nos perfis de sensibilidade já haviam sido anteriormente observadas por outros autores. ${ }^{15,37}$ Do mesmo modo que ocorrido em outras oportunidades, como nos Estados Unidos, ${ }^{11,107}$ Suíça, ${ }^{39}$ Alemanha, ${ }^{54,11}$ Inglaterra ${ }^{8,63,105}$ e Japão, ${ }^{59,61,76,96}$ a origem da infecção não foi esclarecida (Tabelas 1 e 2).

Segundo Pesavento et al, ${ }^{84}$ (2007) várias doenças estão reemergindo e algumas hipóteses buscam explicar essa ocorrência: status sanitário da população, migrações, ambientação dos patógenos às novas condições e fatores ambientais, entre outros. Segundo os autores, abrigos animais apresentariam várias condições predisponentes para esse fenômeno: estresse, imunossupressão, superpopulação, alta exposição, alta rotatividade animal, desnutrição e uso indiscriminado de antibióticos, tornando-se um fator de risco para a população humana e animal.

Esses fatos motivaram a realização de um levantamento microbiológico em cães aparentemente saudáveis de um abrigo de animais. De um grupo de apenas 60 cães cujas amostras de secreções nasais e oculares e lesões de pele foram analisadas, foi detectado um cão fêmea portador assintomático de C. ulcerans. ${ }^{19}$

O encontro de C. ulcerans no ambiente infectando e/ou colonizando humanos e/ou cães ${ }^{19,70}$ sugere que a escassez de dados epidemiológicos em nosso País pode estar relacionada ao fato de os clínicos e os microbiologistas não estarem atentos para a possibilidade de infecção e desconhecerem aspectos clínicos e microbiológicos de processos infecciosos causados pelo C. ulcerans. Ademais, não existem procedimentos de rotina que permitam o isolamento e identificação do patógeno nos laboratórios clínicos.

\section{DIAGNÓSTICO BACTERIOLÓGICO: ESQUEMA DE TRIAGEM}

As epidemias de difteria ocorridas nas últimas décadas têm forçado uma geração de clínicos, laboratoristas

'Marquezi D. Algo novo no reino dos humanos. Galileu. 2007;(197):41-53.

i Ministério da Saúde, Secretaria de Vigilância em Saúde, Coordenação de Vigilância das Doenças de Transmissão Respiratória e

Imunopreveníveis. Informe sobre a difteria no Brasil: alerta sobre o cenário atual [nota técnica]. Brasília (DF); 2010 [citado 2010 nov 17]. Nota técnica. Disponível em: http://portal.saude.gov.br/portal/arquivos/pdf/nt_difteria_29_09_2010.pdf 
e epidemiologistas em diversas partes do mundo a relembrar velhas lições e desenvolver novos métodos de diagnóstico microbiológico, prevenção, controle e tratamento da difteria. , $17,21,26,27-29,35$ Em países emergentes, nos quais a incidência de difteria permanece relativamente alta e a cobertura vacinal continua insuficiente, o suporte laboratorial deve ser implementado diante das deficiências recorrentes nesse segmento. ${ }^{30}$

É indispensável a triagem acurada, rápida, econômica e de fácil execução, capaz de permitir a realização do diagnóstico presuntivo de casos de difteria causados tanto pelo C. ulcerans quanto pelo $C$. diphtheriae na maioria dos laboratórios brasileiros, visando à redução de subnotificações decorrentes de resultados laboratoriais falso-negativos.

Na Figura 3, o algoritmo proposto permite o isolamento de bastonetes Gram-positivos potencialmente produtores de TD utilizando-se meios de cultura (agar sangue e agar chocolate telurito) e testes bioquímicos rotineiramente utilizados nos laboratório de bacteriologia clínica (atividade deoxinucleásica [DNAse], hidrólise da uréia e reação de CAMP-reverso utilizando cepa de Staphylococcus aureus produtora de beta-lisina). Na possibilidade da utilização do meio de Tinsdale podem ser descartadas as amostras de BGPIs cistinasenegativas. Amostras cistinase-positivas e produtoras de

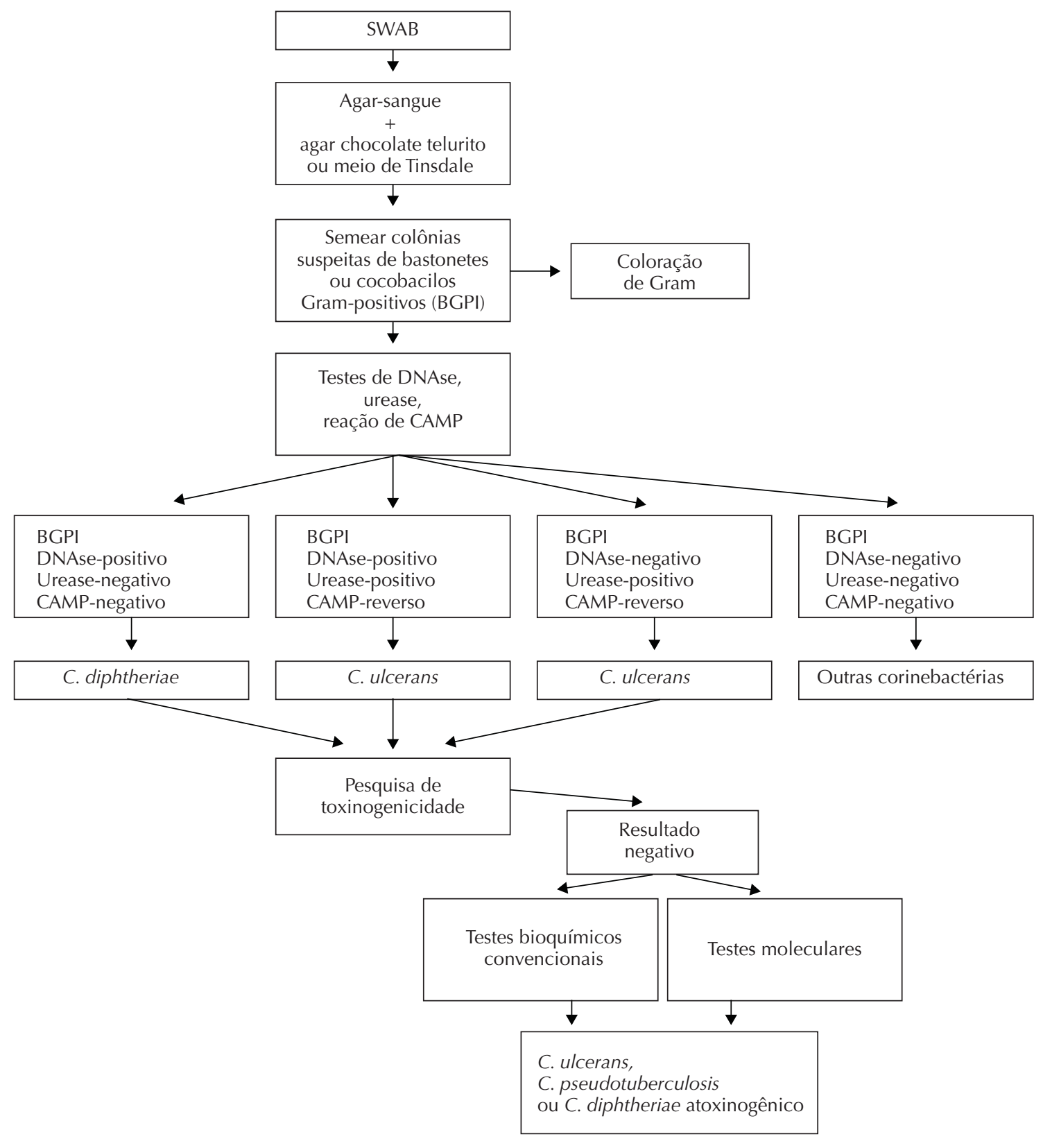

Figura 3. Esquema para triagem de Corynebacterium ulcerans. 
$\mathrm{H}_{2} \mathrm{~S}$, são identificadas pela presença de halo marrom em torno da colônia. ${ }^{30,36}$

Os resultados positivos no teste de DNAse ${ }^{88}$ sugerem a presença de $C$. diphtheriae e de C. ulcerans. Ao contrário de $C$. diphtheriae, as amostras de C. ulcerans são urease-positivas e fazem reação de CAMPreverso. ${ }^{35}$ Raras vezes podem ser isoladas amostras de C. pseudotuberculosis potencialmente produtoras de TD que apresentam resultados negativos nos testes de DNAse e positivos nos testes de cistinase, urease e CAMP-reverso. Amostras cistinase-negativas e DNAse-negativas devem ser consideradas como "outros corineformes".

Além dos testes bioquímicos convencionais, o sistema semi-automatizado API Coryne (BioMérrieux, Lyon, França) também é capaz de identificar esses patógenos, incluindo as amostras atípicas de C. ulcerans e de $C$. diphtheriae fermentadoras de sacarose freqüentemente isoladas no Brasil. ${ }^{33,67}$

Os laboratórios que não apresentarem recursos diponíveis para a execução de testes de toxinogenicidade deverão enviar as cepas para análises complementares ao Laboratório Central de Saúde Pública de sua região e/ou ao Laboratório de Referência Nacional e ao Centro Colaborador em difteria. Os laboratórios que apresentarem recursos diponíveis para a execução de técnicas moleculares capazes de identificar $C$. diphtheriae e $C$. ulcerans e determinar a presença do gene to $x^{9,79,80,86,87}$ também deverão enviar as cepas aos mesmos laboratórios competentes para que seja realizado o controle epidemiológico.

Considerando o curto período de incubação da doença (de um a seis dias), recomenda-se a coleta de material para pesquisa de C. ulcerans e C. diphtheriae (naso e orofaringe e de lesão de pele) de pessoas e animais que tiveram contato com o caso (suspeito ou confirmado) nos últimos 10 a 14 dias.

\section{PAPEL DO TOXÓIDE DIFTÉRICO NA PREVENÇÃO}

A concentração de anticorpos protetores em indivíduos adultos decresce $10 \%$ ao ano. ${ }^{98}$ A importância de programas de reforço vacinal na população adulta foi comprovada na Finlândia. ${ }^{78}$ Os dados disponíveis na literatura relativos à cobertura vacinal de indivíduos jovens e adultos no Brasil são escassos. ${ }^{15,20,22,85,102} \mathrm{Na}$ cidade do Rio de Janeiro, somente 30\% dos adultos estão completamente protegidos contra a ação da TD, ${ }^{15}$ à semelhança do observado em outros países, como a Turquia. ${ }^{10}$ Esses dados enfatizam a importância da aplicação de doses de reforço com o toxóide diftérico a cada dez anos a fim de evitar decréscimos nos níveis de anticorpos da população. ${ }^{10,20}$
Entretanto, a eficácia do toxóide diftérico contra a difteria zoonótica causada pelo C. ulcerans ainda permanece desconhecida. Os estudos relacionados na Tabela 1 mostraram que a maioria (aproximadamente $75 \%$ ) dos casos de difteria zoonótica tem ocorrido em pacientes adultos que haviam sido total ou parcialmente vacinados com toxóide diftérico.

Ainda existem muitos aspectos que necessitam de melhor avaliação não só no âmbito do diagnóstico clínico-laboratorial, mas também no tratamento e na prevenção das doenças causadas pelo C. ulcerans. Da mesma forma, uma melhor compreensão da epidemiologia molecular e das características de C. ulcerans, bem como da toxina produzida que se assemelha à TD de $C$. diphtheriae.

Estudos recentes revelaram diferenças na seqüência de nucleotídeos entre os genes tox de C. ulcerans e $C$. diphtheriae, bem como entre genes tox de diferentes amostras de C. ulcerans. Algumas amostras isoladas de pacientes apresentando quadro de infecção extrafaringeal apresentaram diferenças nas seqüências da TD, predominantemente nos domínios de translocação e de aderência. . $^{90,80,99,109}$

Esses fatos podem contribuir para que os indivíduos vacinados com toxóide diftérico ou submetidos à soroterapia não apresentem proteção total contra as infecções causadas pelo C. ulcerans. Mesmo que seja considerada a possibilidade de um efeito protetor do toxóide diftérico contra a difteria causada pelo C. ulcerans (ou seja, pela presença de sintomas clínicos atenuados), deve-se lembrar que a vacinação só previne a ação da TD e provavelmente não impede a colonização por corinebactérias toxigênicas. Os pesquisadores concordam que, na falta de uma vacina comprovada contra C. ulcerans, o toxóide diftérico permanece uma alternativa razoável, especialmente nos casos de convalescentes. Por outro lado, ainda consideram que são escassas as evidências de que a vacinação com o toxóide diftérico, mesmo quando atualizada, impedirá a difteria zoonótica ou outras doenças causadas pelo C. ulcerans. ${ }^{94,107}$

\section{CONSIDERAÇÕES FINAIS}

A circulação de C. ulcerans em vários países, somada aos recentes casos descritos no Brasil de infecções ocorridas em humanos e animais, permite aventar a hipótese da ocorrência de difteria zoonótica e a circulação do C. ulcerans em regiões urbanas e rurais do País. Há, portanto, necessidade de adequação dos protocolos de diagnóstico microbiológico de $C$. ulcerans além de $C$. diphtheriae, utilizando métodos alternativos de triagem que possam ser implantados nos laboratórios da rede pública e privados. A implementação da vigilância epidemiológica e laboratorial poderá contribuir para um aumento no número de casos confirmados de difteria clássica e zoonótica no Brasil. 


\section{REFERÊNCIAS}

1. Aaron L, Heurtebise F, Bachelier MN, Guimard Y. Angine diphtérique pseudomembraneuse autochtone liée à Corynebacterium ulcerans. Rev Med Interne. 2006;27(4):333-5. DOI:10.1016/j.revmed.2005.12.011

2. Barret NJ. Comunicable disease associated with milk and dairy products in England and Wales. J Infec. 1986;12(3):265-72.

3. Bergin II, Chien CC, Marini RP, Fox JG. Isolation and characterization of Corynebacterium ulcerans from cephalic implants in macaques. Comp Med. 2000;50(5):530-5.

4. Bitragunta S, Murhekar MV, Chakravarti A, Verma V, Namjoshi GS, Parekh SS, et al. Safety and immunogenicity of single dose of tetanus-diphtheria (Td) vaccine among non/partially immune children against diphtheria and/or tetanus, Hyderabad, India, 2007. Vaccine. 2010;28(37):5934-8. DOI:10.1016/j. vaccine.2010.06.047

5. Bonmarin I, Guiso N, Le Flèche-Matéos A, Patey O, Patrick AD, Levy-Bruhl D. Diphtheria: a zoonotic disease in France? Vaccine. 2009;27(31):4196-200. DOI:10.1016/j.vaccine.2009.04.048

6. Bonnet JM, Begg NT. Control of diphtheria: guidance for consultants in communicable disease control. Commun Dis Public Health. 1999;2(4):242-9.

7. Bostock AD, Gilbert FR, Lewis D, Smith DCM. Corynebacterium ulcerans infection associated with untreated milk. J Infect. 1984;9(3):286-8.

8. Carpentier JP, Flanagan PM, Singh JP, Timms MS, Nassar WY. Nasopharyngeal Corynebacterium ulcerans: a different diphtheria. J Laryngol Otol. 1992;106(9):824-6

9. Cassiday PK, Pawloski LC, Tiwari T, Sanden GN, Wilkins PP. Analysis of toxigenic Corynebacterium ulcerans strains revealing potential for false-negative real-time PCR results. J Clin Microbiol. 2008;46(1):3313. DOI:10.1128/JCM.01251-07

10. Cavus SA, Oguz VA, Yuce A. The seroprevalence of diphtheria among adults in Izmir-Turkey. Vaccine. 2007;25(19):3851-4. DOI:10.1016/j. vaccine.2007.01.104

11. Centers for Disease Control and Prevention. Respiratory diphtheria caused by Corynebacterium ulcerans -Terre Haute, Indiana, 1996. MMWR Morb Mortal Wkly Rep. 1997;46(15):330-2.

12. Centers for Disease Control and Prevention. Three cases of toxigenic Corynebacterium ulcerans infection. Commun Dis Rep CDR Wkly. 2000;10(6):49, 52.

13. Colombo AV, Hirata Jr R, Souza CM, Monteiro-Leal LH, Previato JO, Formiga LC, et al. Corynebacterium diphtheriae surface proteins as adhesins to human erythrocytes. FEMS Microbiol Lett. 2001;197(2):235-9.

14. Coyle MB, Minshew BH, Bland JA, Hsu PC. Erythromycin and clindamycin resistance in Corynebacterium diphtheriae from skin lesions. Antimicrob Agents Chemoter. 1979;16(4):525-7.

15. Damasco PV, Pimenta FP, Filardy AA, Brito SM, Andrade AF, Lopes GS, et al. Prevalence of IgG diphtheria antitoxin in blood donors in Rio de Janeiro. Epidemiol Infect. 2005;133(5):911-4. DOI:10.1017/ S0950268805003997

16. Dessau RB, Brandt-Christensen M. Jensen OJ, Tonnesen P. Pulmonary nodules due to Corynebacterium ulcerans. Eur Respir J. 1995;(4)8:651-3. DOI:10.1183/0 9031936.95.08040651

17. Dewinter LM, Bernard KA, Romney MG. Human clinical isolates of Corynebacterium diphtheriae and Corynebacterium ulcerans collected in Canada from 1999 to 2003 but not fitting reporting criteria for cases of diphtheria. J Clin Microbiol. 2005;43(7):3447-9. DOI:10.1128/JCM.43.7.3447-3449.2005

18. De Zoysa A, Hawkey PM, Engler K, George R, Mann G, Reilly W, et al. Characterization of toxigenic Corynebacterium ulcerans strains isolated from humans and domestic cats in the United Kingdom. J Clin Microbiol. 2005;4(9):4377-81. DOI:10.1128/ JCM.43.9.4377-4381.2005

19. Dias AASO, Silva Jr FC, Pereira GA, Souza MC, Camello TCF, Damasceno JALD, et al. Corynebacterium ulcerans isolated from an asymptomatic dog kept in an animal shelter in the metropolitan area of Rio de Janeiro, Brazil. Vector Borne Zoonotic Dis. 2010;10(8):743-8. DOI:10.1089/ vbz.2009.0132

20. Dinelli MIS, Fisberg M, Moraes-Pinto MI. Tetanus and diphtheria immunity in adolescents from São Paulo, Brazil. Braz J Med Biol Res. 2007;40(2):259-63. DOI:10.1590/S0100-879X2006005000070

21. Dittmann S, Wharton M, Vitek C, Ciotti M, Galazka A, Guichard S, et al. Successful control of epidemic diphtheria in the State of Former Union of Soviet Socialist Republics: lessons learned. J Infect Dis. 2000;181 Suppl 1:S10-22. DOI:10.1086/315534

22. Divino-Goes KG, Moraes-Pinto MI, Dinelli MIS, Casagrande ST, Bonetti TC, Andrade PR, et al. Prevalence of diphtheria and tetanus antibodies and circulation of Corynebacterium diphtheriae in São Paulo, Brazil. Braz J Med Biol Res. 2007;40(12):16817. DOI:10.1590/S0100-879X2006005000183

23. Durbacă S. Antitetanus and antidiphtheria immunity in newborns. Roum Arch Microbiol Immunol. 1999;58(34):267-72.

24. Dzupova O, Benes J, Kriz B, Horová B, Olexová A. [An unusual course of invasive infection due to nontoxinogenic strain of Corynebacterium diphtheria]. Klin Mikrobiol Infekc Lek. 2005;11(6):222-5.

25. Elden S, Coole L, Efstratiou A, Doshi N. Laboratoryconfirmed case of toxigenic Corynebacterium ulcerans. Euro Surveill. 2007;12(3)E070329.3

26. Efstratiou A, Engler KH, Dawes CS, Sadic D. Comparison of phenotypic and genotypic methods for detection of diphtheria toxin among isolates of pathogenic corynebacteria. J Clin Microbiol. 1998;36(11):3173-7.

27. Efstratiou A, George RC. Laboratory guidelines for the diagnosis of infections caused by Corynebacterium diphtheriae and C. ulcerans. Commun Dis Public Health. 1999;2(4):250-7. 
28. Efstratiou A, Engler KH, Mazurova IK, Glushkevish T, Vuopio-Varkila J, Popovic T. Current approaches to the laboratory diagnosis of diphtheria. J Infect Dis. 2000;181(Suppl 1):S138-45. DOI:10.1086/315552

29. Farizo KM, Strebel PM, Chen RT, Kimbler A, Cleary TJ, Cochi SL. Fatal respiratory disease due to Corynebacterium diphtheriae: case report and review of guidelines for management, investigation and control. Clin Infect Dis. 1993;16(1):59-68. DOI:10.1093/clinids/16.1.59

30. Formiga LCD, Mattos-Guaraldi AL. Diphtheria: current status and laboratory procedures for diagnosis. Rev Bras Patol Clin. 1993;29(3):93-6.

31. Foster G, Patterson T, Howie F, Simpson V, Davison N, Efstratiou A, et al. Corynebacterium ulcerans in freeranging otters. Vet Rec. 2002;150(16):524.

32. Fox JG, Frost WW. Corynebacterium ulcerans mastitis in a bonnet macaque (Macaca radiata). Lab Anim Sci. 1974;24(5):820-2.

33. Funke G, von Graevenitz A, Clarridge JE 3rd, Bernard KA. Clinical microbiology of coryneform bacteria. Clin Microbiol Rev. 1997;10(1):125-59.

34. Funke G, Bernard KA. Coryneform gram-positive rods. In: Murray PR, Baron EJ, Jorgensen JH, Landry MA, Pfaller MA, editors. Manual of clinical microbiology. Washington (DC): American Society for Microbiology Press; 2007. p.485-514.

35. Galazka AM, Robertson SE. Diphtheria: changing patterns in the developing world and the industrialized world. Eur J Epidemiol. 1995;11(1):107-17.

36. Galazka AM. The changing epidemiology of diphtheria in the vaccine era. J Infect Dis. 2000;181(Suppl 1):S29. DOI:10.1086/315533

37. Gilbert R, Stewart FC. Corynebacterium ulcerans: a pathogenic microorganism resembling C. diphtheriae. J Lab Clin Med. 1926;12:756-61.

38. Gladin DP, Koslova NS, Zaitseva TK, Cherednichenko AS, Khval SA. [Sensitivity of Corynebacterium diphtheriae isolated in Saint Petersburg to antibacterial drugs]. Antibiot Khimioter. 1999;44(5):17-21.

39. Groman N, Schiller J, Russell J. Corynebacterium ulcerans and Corynebacterium pseudotuberculosis responses to DNA probes derived from corynephage beta and Corynebacterium diphtheriae. Infect Immun. 1984;45(2):511-7.

40. Gubler JG, Wüst J, Krech T, Hany A. [Classical pseudomembranous diphtheria caused by Corynebacterium ulcerans]. Schweiz Med Wochenschr. 1990;120(48):1812-6.

41. Hadfield TL, McEvoy P, Polotsky Y, Tzinserling VA, Yakovlev AA. The pathology of diphtheria. J Infect Dis. 2000;181(Suppl 1):S116-20. DOI:10.1086/315551

42. Hall AJ, Cassiday PK, Bernard KA, Bolt F, Steigerwalt AG, Bixler D, et al. Novel Corynebacterium diphtheriae in domestic cats. Emerg Infect Dis. 2010;16(4):688-91. DOI:10.3201/eid1604.091107

43. Hard GC. Comparative toxic effect of the surface lipid of Corynebacterium ovis on peritoneal macrophages. Infect Immun. 1975;12(6):1439-49.
44. Hart RJC. Corynebacterium ulcerans in humans and cattle in North Devon. J Hyg (Lond). 1984;92(2):161-4.

45. Hatanaka A, Tsunoda A, Okamoto M, Ooe K, Nakamura A, Miyakoshi M, et al. Corynebacterium ulcerans diphtheria in Japan. Emerg Infect Dis. 2003;9(6):752-3. DOI:10.3201/eid0906.020645

46. Henriksen SD. Some bacteriophages of Corynebacterium ulcerans and their lack of effect on toxigenicity. Acta Pathol Microbiol Scand. 1955;37(1):65-70.

47. Higgs TM, Smith A, Cleverly LM, Neave FK. Corynebacterium ulcerans infections in a dairy herd. Vet Rec. 1967;81(2):34-5.

48. Hirata Jr R, Napoleão F, Monteiro-Leal LH, Andrade AF, Nagao PE, Formiga LC, et al. Intracellular viability of toxigenic Corynebacterium diphtheriae strains in HEp-2 cells. FEMS Microbiol Lett. 2002;215(1):115-9.

49. Hirata Jr R, Pereira GA, Filardy AA, Gomes DLR, Damasco PV, Rosa ACP, et al. Potential pathogenic role of aggregative-adhering Corynebacterium diphtheriae of different clonal groups in endocarditis. Braz / Med Biol Res. 2008;41(11):986-91. DOI:10.1590/S0100879X2008001100007

50. Hirata Jr R, Souza SM, Rocha-de-Souza CM, Andrade AF, Monteiro-Leal LH, Formiga LC, et al. Patterns of adherence to HEp-2 cells and actin polymerisation by toxigenic Corynebacterium diphtheriae strains. Microb Pathog. 2004;36(3):125-30. DOI:10.1016/j. micpath.2003.10.002

51. Hodgson AL, Krywult J, Corner LA, Rothel JS, Radford AJ. Rational attenuation of Corynebacterium pseudotuberculosis: potential cheesy gland vaccine and live delivery vehicle. Infect Immun. 1992;60(7):2900-5.

52. Hogg RA, Wessels J, Hart J, Efstratiou A, De Zoysa A, Mann G, et al. Possible zoonotic transmission of toxigenic Corynebacterium ulcerans from companion animals in a human case of fatal diphtheria. Vet Rec. 2009;165(23):691-2. DOI:10.1135/vr.165.23.691

53. Hommez J, Devriese LA, Vaneechoutte M, Riegel P, Butaye P, Haesebrouck F. Identification of nonlipophilic corynebacteria isolated form dairy cows with mastitis. J Clin Microbiol. 1999;37(4):954-7.

54. Honma Y, Nakasone N. Pili of Aeromonas hydrophila: purification, characterization and biological role. Microbiol Immunol. 1989;34(2):83-98.

55. Hust MH, Metzler U, Schubert AW, Seuffer RH. Toxische diphtherie durch Corynebacterium ulcerans. Dtsch Med Wochenschr. 1994;119(15):548-52.

56. Katsukawa C, Kawahara R, Inoue K, Ishii A, Yamagishi $\mathrm{H}$, Kida K, et al. Toxigenic Corynebacterium ulcerans isolated from the domestic dog for the first time in Japan. Jpn J Infect Dis. 2009;62(2):171-2.

57. Kaufmann D, Ott P, Ruegg C. Laryngopharyngitis by Corynebacterium ulcerans. Infection. 2002;30(3):16870.

58. Khamis A, Raoult D, La Scola B. Rpo B gene sequencing for identification for Corynebacterium species. J Clin Microbiol. 2004;42(9):3925-31. DOI:10.1128/JCM.42.9.3925-3931.2004 
59. Khan N, Shastri J, Aigal U, Doctor B. Resurgence of diphtheria in the vaccination era. Indian J Med Microbiol. 2007;25(4):434. DOI:10.4103/02550857.37367

60. Kimura Y, Watanabe Y, Suga N, Suzuki N, Maeda K, Suzuki K, et al. Acute peritonitis due to Corynebacterium ulcerans in a patient receiving continuous ambulatory peritoneal dialysis: a case report and literature review. Clin Exp Nephrol. 2011;15(1):171-4. DOI:10.1007/s10157-010-0346-4

61. Kisely SR, Price S, Ward T. Corynebacterium ulcerans: a potential cause of diphtheria. Commun Dis Rep CDR Rev. 1994;4(5):63-4.

62. Komiya T, Seto Y, De Zoysa A, Iwaki M, Hatanaka A, Tsunoda A, et al. Two Japanese Corynebacterium ulcerans isolates from the same hospital: ribotype, toxigenicity, and serum antitoxin titre. / Med Microbiol. 2010;59(Pt 12):1497-504. DOI:10.1099/ jmm.0.022491-0

63. Lartigue MF, Monnet X, Le Flèche A, Grimont PA, Benet JJ, Durrbach A, et al. Corynebacterium ulcerans in an immunocompromised patient with diphtheria and her dog. I Clin Microbiol. 2005;43(2):999-1001. DOI:10.1128/JCM.43.2.999-1001.2005

64. Leek MD, Sivaloganathan S, Devaraj SK, Zamiri I, Griffiths GD, Green MA. Diphtheria with a difference: a rare corynebacterium fatality with associated apoptotic cell death. Histopathology. 1990;16(2):187-9.

65. Leggett BA, De Zoyza A, Abbott YE, Leonard N, Markey B, Efstratiou A. Toxigenic Corynebacterium diphtheriae isolated from a wound in a horse. Vet Rec. 2010;166(21):656-7. DOI:10.1136/vr.b4846

66. Man P, Montagner C, Vitrac H, Kavan D, Pichard S, Gillet D, et al. Accessibility changes within diphtheria toxin $\mathrm{T}$ domain when in the functional molten globule state, as determined using hydrogen/deuterium exchange measurements. FEBS J. 2010;277(3):653-62. DOI:10.1111/j.1742-4658.2009.07511.x

67. Mattos-Guaraldi AL, Formiga LCD. Bacteriological properties of a sucrose-fermenting Corynebacterium diphtheriae strain isolated from a case of endocarditis. Curr Microbiol. 1998;37(3):156-8. DOI:10.1007/ s002849900356

68. Mattos-Guaraldi AL, Formiga LC, Andrade AF. Transsialidase activity for sialic acid incorporation on Corynebacterium diphtheriae. FEMS Microbiol Lett. 1998;168(2):167-72.

69. Mattos-Guaraldi AL, Formiga LCD, Marques EA, Pereira GA, Moreira LO, Pimenta FP, et al. Diphtheria in a vaccinated adult in Rio de Janeiro, Brazil. Braz J Microbiol. 2001;32(3):236-9. DOI:10.1590/S151783822001000300015

70. Mattos-Guaraldi AL, Moreira LO, Damasco PV, Hirata Jr R. Diphtheria remains a threat to health in the developing world: an overview. Mem Inst Oswaldo Cruz. 2003;98(8):987-93. DOI:10.1590/S007402762003000800001

71. Mattos-Guaraldi AL, Sampaio JLM, Santos CS, Pimenta FP, Pereira GA, Pacheco LGC, et al. First detection of Corynebacterium ulcerans producing diphtheria-like toxin in a case of human with pulmonary infection in the Rio de Janeiro metropolitan area, Brazil. Mem Inst Oswaldo Cruz. 2008;103(4):396-400. DOI:10.1590/ S0074-02762008000400014

72. May BD. Corynebacterium ulcerans infections in monkeys. Lab Anim Sci. 1972;22(4):509-13.

73. McNamara PJ, Cuevas WA, Songer JG. Toxic phospholipases D of Corynebacterium pseudotuberculosis, C. ulcerans and Arcanobacterium haemolyticum: cloning and sequence homology. Gene. 1995;156(1):113-8. DOI:10.1016/0378$1119(95) 00002-\mathrm{N}$

74. Moreira LO, Andrade AF, Vale MD, Souza SM, Hirata Jr R, Asad LM, et al. Effects of iron limitation on adherence and cell surface carbohydrates of Corynebacterium diphtheriae strains. Appl Environ Microbiol. 2003;69(10):5907-13. DOI:10.1128/ AEM.69.10.5907-5913.2003

75. Morris WE, Uzal FA, Cipolla AL. Pyogranulomatous meningoencephalitis in a goat due to Corynebacterium ulcerans. Vet Rec. 2005;156(10):317-8.

76. Nielsen PB, Scherling B, Scheibel JH, Frederiksen W. [Diphtheria in Denmark 1956-1989. Occurrence of Corynebacterium diphtheriae and other diphtheria toxigenic bacteria]. Ugeskr Laeger. 1991;153(11):76972 .

77. Nureki S, Miyazaki E, Matsuno O, Takenaka R, Ando $\mathrm{M}$, Kumamoto T, et al. Corynebacterium ulcerans infection of the lung mimicking the histology of Churg-Strauss syndrome. Chest. 2007;131(4):1237-9. DOI:10.1378/chest.06-2346

78. Ölander RM, Auranen K, Härkänen T, Leino T. High tetanus and diphtheria antitoxin concentrations in Finnish adults: time for new booster recommendations? Vaccine. 2009;27(39):5295-8. DOI:10.1016/j. vaccine.2009.06.080

79. Olson ME, Goemans I, Bolingbroke D, Lundberg S. Gangrenous dermatitis caused by Corynebacterium ulcerans in Richardson ground squirrels. J Am Vet Med Assoc. 1988;193(3):367-8.

80. Pacheco LG, Pena RR, Castro TL, Dorella FA, Bahia RC, Carminati R, et al. Multiplex PCR assay for identification of Corynebacterium pseudotuberculosis from pure cultures and for rapid detection of this pathogen in clinical samples. J Med Microbiol. 2007;56(Pt 4):480-6. DOI:10.1099/jmm.0.46997-0

81. Pallen MJ, Hay AJ, Puckey LH, Efstratiou A. Polymerase chain reaction for screening clinical isolates of corynebacteria for the production of diphtheria toxin. J Clin Pathol. 1994;47(4):353-6.

82. Panaitescu M, Maximescu P, Michel J, Potorac E. Respiratory pathogens in non-human primates with special reference to Corynebacterium ulcerans. Lab Anim. 1977;11(3):155-7.

83. Pappenheimer AM Jr. The story of a toxic protein, 1888-1992. Protein Sci. 1993;2(2):292-8. DOI:10.1002/pro.5560020218

84. Pers C. Infection due to Corynebacterium ulcerans, producing diphtheria toxin: a case report from Denmark. Acta Pathol Microbiol Immunol Scand B. 1987;95(6):361-2. 
85. Pesavento PA, Bannasch MJ, Bachmann R, Byrne BA, Hurley KF. Fatal Streptococcus canis infections in intensively housed shelter cats. Vet Pathol. 2007; 44(2):218-21. DOI:10.1354/vp.44-2-218

86. Pimenta FP, Damasco PV, Cerbino Neto J, Lopes GS, Hirata Jr R, Milagres LG, et al. Diphtheria-neutralizing antibody levels in healthy adults from Rio de Janeiro, Brazil. Mem Inst Oswaldo Cruz. 2006;101(4):459-62. DOI:10.1590/S0074-02762006000400018

87. Pimenta FP, Hirata Jr R, Rosa AC, Milagres LG, MattosGuaraldi AL. A multiplex PCR assay for simultaneous detection of Corynebacterium diphtheriae and differentiation between non-toxigenic and toxigenic isolates. J Med Microbiol. 2008;57(Pt 11):1438-9. DOI:10.1099/jmm.0.2008/000414-0

88. Pimenta FP, Matias GA, Pereira GA, Camello TC, Alves GB, Rosa AC, et al. A PCR for dtxR gene: application to diagnosis of non-toxigenic and toxigenic Corynebacterium diphtheriae. Mol Cell Probes. 2008;22(3):189-92. DOI:10.1016/j.mcp.2008.01.001

89. Pimenta FP, Souza MC, Pereira GA, Hirata Jr R, Camello TC, Mattos-Guaraldi AL. DNase test as a novel approach for the routine screening of Corynebacterium diphtheriae. Lett Appl Microbiol. 2008;46(3):307-11. DOI:10.1111/j.1472-765X.2007.02310.x

90. Popovic T, Kombarova S, Reeves MW, Nakao H, Mazurova IK, Wharton M, et al. Molecular epidemiology of diphtheria in Russia, 1985-1994. J Infect Dis. 1996;174(5):1064-72. DOI:10.1093/ infdis/174.5.1064

91. Popovic T, Mazurova IK, Efstratiou A, VuopioVarkila J, Reeves MW, De Zoyza A, et al. Molecular epidemiology of diphtheria. J Infect Dis. 2000;181 (Suppl 1):S168-77. DOI:10.1086/315556

92. Riegel P, Ruimy R, de Briel D, Prévost G, Jehl F, Christen R, et al. Taxonomy of Corynebacterium diphtheriae and related taxa, with recognition of Corynebacterium ulcerans sp. nov. nom. rev. FEMS Microbiol Lett. 1995;126(3):271-6.

93. Saikia L, Nath R, Saikia NJ, Choudhury G, Sarkar M. A diphtheria outbreak in Assam, India. Southeast Asian J Trop Med Public Health. 2010;41(3):647-52.

94. Salyers AA, Whitt DD. Bacterial pathogenesis: a molecular approach. Washington (DC): American Society for Microbiology Press; 1994. Diphtheria; p.113-21.

95. Schuhegger R, Kugler R, Sing A. Pitfalls with diphtheria-like illness due to toxigenic Corynebacterium ulcerans. Clin Infect Dis. 2008;47(2):288. DOI:10.1086/589575

96. Schuhegger R, Schoerner C, Dlugaiczyk J, Lichtenfeld I, Trouillier A, Zeller-Peronnet V, et al. Pigs as source for toxigenic Corynebacterium ulcerans. Emerg Infect Dis. 2009;15(8):1314-5. DOI:10.3201/ eid1508.081568

97. Seto Y, Komiya T, Iwaki M, Kohda T, Mukamoto $M$, Tanahashi $M$, et al. Properties of corynephage attachment site and molecular epidemiology of Corynebacterium ulcerans isolated from humans and animals in Japan. Jpn J Infect Dis. 2008;61(2):116-22.
98. Siegel SM, Haile CA. Corynebacterium ulcerans pneumonia. South Med J. 1985;78(10):1267.

99. Simonsen O, Klærke M, Klærke A, Bloch AV, Hansen BR, Hald N, et al. Revaccination of adults against diphtheria. II: Combined diphtheria and tetanus revaccination with different doses of diphtheria toxoid 20 years after primary vaccination. Acta Pathol Microbiol Immunol Scand C. 1986;94(5):219-26.

100. Sing A, Hogardt M, Bierschenk S, Heesemann J. Detection of differences in the nucleotide and amino acid sequences of diphtheria toxin from Corynebacterium diphtheriae and Corynebacterium ulcerans causing extrapharyngeal infections. J Clin Microbiol. 2003;41(10):4848-51. DOI:10.1128/ JCM.41.10.4848-4851.2003

101. Sing A, Bierschenk S, Heesemann J. Classical diphtheria caused by Corynebacterium ulcerans in Germany: amino acid sequence differences between diphtheria toxins from Corynebacterium diphtheriae and C. ulcerans. Clin Infec Dis. 2005;40(2):325-6. DOI:10.1086/426687

102. Souza SMS, Hirata Jr R, Moreira LO, Gomes ML, Andrade AFB, Bernardo-Filho M, et al. Influence of stannous chloride on the adhesive properties of Corynebacterium diphtheriae strains. Int J Mol Med. 2003;12(4):657-61.

103. Speranza FAB, Ishii SK, Hirata Jr R, Mattos-Guaraldi AL, Milagres LG. Diphtheria toxin IgG levels in military and civilian blood donors in Rio de Janeiro, Brazil. Braz J Med Biol Res. 2010;43(1):120-3. DOI:10.1590/S0100-879X2009007500032

104. Sykes JE, Mapes S, Lindsay LL, Samitz E, Byrne BA. Corynebacterium ulcerans bronchopneumonia in a dog. J Vet Intern Med. 2010;24(4):973-6. DOI:10.1111/j.1939-1676.2010.0491.x

105. Taylor DJ, Efstratiou A, Reilly WJ. Diphtheria toxin production by Corynebacterium ulcerans from cats. Vet Rec. 2002;150(11):355.

106. Taylor J, Saveedra-Campos M, Harwood D, Pritchard G, Raphaely N, Kapadia S, et al. Toxigenic Corynebacterium ulcerans infection in a veterinary student in London, United Kingdom, May 2010. Euro Surveill. 2010;15(31):1-3.

107. Tejedor Mt, Martin JL, Lupiola P, Gutierrez C. Caseous lymphadenitis caused by Corynebacterium ulcerans in the dromedary camel. Can Vet J. 2000;41(2):126-7.

108. Tiwari TS, Golaz A, Yu DT, Ehresmann KR, Jones TF, Hill $\mathrm{HE}$, et al. Investigations of 2 cases of diphtherialike illness due to toxigenic Corynebacterium ulcerans. Clin Infect Dis. 2008;46(3):395-401. DOI: $10.1086 / 525262$

109. Van Dam AP, Schippers EF, Visser LG, Peek N, Swaan CM, Kuijper EJ. A case of diphtheria in the Netherlands due to an infection with Corynebacterium ulcerans. Ned Tijdschr Geneeskd. 2003;147(9):403-6.

110. Vertiev YuV, Ezepchuk YuV, Souckova A, Soucek A. Purification and some properties of exotoxin from Corynebacterium ulcerans strain ATCC 9015. Zentralbl Bakteriol Mikrobiol Hyg A. 1981;249(4):527-37. 
111. Von Hunolstein C, Alfarone G, Scopetti F, Pataracchia M, La Valle R, Franchi F, et al. Molecular epidemiology and characteristics of Corynebacterium diphtheriae and Corynebacterium ulcerans strains isolated in Italy during the 1990s. J Med Microbiol. 2003;52(Pt 2):181-8. DOI:10.1099/jmm.0.04864-0

112. Wagner J, Ignatius R, Voss S, Höpfner V, Ehlers $S$, Funke $G$, et al. Infection of the skin caused by Corynebacterium ulcerans and mimicking classical cutaneous diphtheria. Clin Infect Dis. 2001;33(9):1598-600. DOI:10.1086/322969

113. Wagner KS, White JM, Crowcroft NS, De Martin S, Mann G, et al. Diphtheria in the United Kingdom, 1986-2008: the increasing role of Corynebacterium ulcerans. Epidemiol Infect. 2010;138(11):1519-30. DOI:10.1017/S0950268810001895

114. Wagner KS, White JM, Neal S, Crowcroft NS, Kupreviciene N, Paberza R, et al. Screening for
Corynebacterium diphtheriae and Corynebacterium ulcerans in patients with upper respiratory tract infections 2007-2008: a multicentre European study. Clin Microbiol Infect Dis, 2011;17(4):519-25. DOI:10.1111/j.1469-0691.2010.03269.x

115. Wang J, London E. The membrane topography of the diphtheria toxin $\mathrm{T}$ domain linked to the a chain reveals a transient transmembrane hairpin and potential translocation mechanisms. Biochemistry. 2009;48(43):10446-56. DOI:10.1021/bi9014665

116. Wellinghausen N, Sing A, Kern WV, Perner S, Marre $\mathrm{R}$, Rentschler J. A fatal case of necrotizing sinusitis due to toxigenic Corynebacterium ulcerans. Int J Med Microbiol. 2002;292(1):59-63.

117. Wong TP, Groman N. Production of diphtheria toxin by selected isolates of Corynebacterium ulcerans and Corynebacterium pseudotuberculosis. Infect Immun. 1984;43(3):1114-6.

Pesquisa financiada pela Fundação de Amparo à Pesquisa do Estado do Rio de Janeiro (FAPERJ - Processos $\mathrm{n}^{\circ}$ : E-26/101519/2010; E-26/11.278/2010;E-26/102.146/2010; E-26/110.339/2010); pelo Conselho Nacional de Desenvolvimento Científico e Tecnológico (CNPq - Processos n: 470357/2009-6;302897/2007-0; 502090/2010-3); pela Coordenação de Aperfeiçoamento de Pessoal de Nível Superior (Capes - Processo n: 0370088); pelo Instituto Nacional de Controle de Qualidade em Saúde -Fundação Oswaldo Cruz (INCQS/Fiocruz - Processos nº: 403626/2008-0; 03621/2008-9). Santos LS e Silva Júnior FC foram apoiados pela Subreitoria de Pós-Graduação e Pesquisa/Universidade do Estado do rio de Janeiro (bolsistas de Iniciação Científica).

Os autores declaram não haver conflitos de interesses. 